\title{
Physiological responses to intensive snow shoveling performed by volunteers in heavy snowfall area
}

\author{
Tsutomu SUDA $^{1 *}$, Kazuki TAKIZAWA ${ }^{2}$, Nobuyoshi KONISHI ${ }^{3}$, Satoshi OMIYA \\ and Shun TSUTAKI ${ }^{5}$ \\ 1 Non-profit Organization Snow and Ice Network, Sapporo 007-0840, Japan \\ *sudariki@poppy.ocn.ne.jp \\ 2 Institute of Physical Development Research, Sapporo 060-0061, Japan \\ 3 Hokkaido Development Engineering Center, Sapporo 001-0011, Japan \\ 4 Civil Engineering Research Institute for Cold Regions, Sapporo 062-8602, Japan \\ 5 Atmosphere and Ocean Research Institute, The University of Tokyo, Kashiwa 277-8564, Japan
}

(Received April 23, 2019; Revised manuscript accepted September 18, 2019)

\begin{abstract}
The purpose of this study was to examine the physiological responses to intensive snow shoveling. The subjects were six males (25-71, 50土8 years) who participated in a snow removal volunteer tour. Prior to the tour, each subject engaged in a cycle ergometer test (Test 1) and a multistage shoveling test (Test 2) to evaluate the relationship between volume of oxygen consumption $\left(\mathrm{V}_{2}\right)$ and heart rate. Field measurements were performed in Miruto of Iwamizawa City, Hokkaido, Japan on February 2, 2014. Average air temperatures of that day were $-6.3{ }^{\circ} \mathrm{C}$ in the morning and $-1.4{ }^{\circ} \mathrm{C}$ in the afternoon. The snow layer at the work site had various grain shapes and snow density linearly increased with snow depth. While snow hardness increased exponentially with increase in snow depth. Mean heart rate during working time in the afternoon $\left(142 \pm 9\right.$ beats $\left.\mathrm{min}^{-1}\right)$ was significantly $(\mathrm{p}<0.01)$ higher than that in the morning $\left(131 \pm 9\right.$ beats $\left.\mathrm{min}^{-1}\right)$. These heart rates correspond $84 \%$ and $77 \%$ of the predicted maximum heart rate $\left(\mathrm{HR}_{\max }\right)$, respectively. Ratings of perceived exertion were not different in the morning (12.9 \pm 0.4$)$ and afternoon $(12.4 \pm 0.3)$. The mean values of $\dot{\mathrm{VO}_{2}}$ in the total work period $\left(111 \pm 3 \mathrm{~min}\right.$ ) was estimated to be $22.2 \pm 1.2 \mathrm{ml} \mathrm{kg}^{-1} \mathrm{~min}^{-1}$ (Metabolic equivalent; $6.4 \pm 0.3 \mathrm{METs}$ ). Estimated energy expenditure averaged $782 \pm 46 \mathrm{kcal}$. It is conceivable that increase in snow hardness and snow density caused an increase in work intensity.
\end{abstract}

Key words: snow shoveling, heart rate, metabolic equivalent (MET), special heavy snowfall area

\section{Introduction}

More than half of the land area of Japan is covered with snow in winter. Many of the heavy snowfall areas are facing problems of depopulation and aging of the population. Daily snow removal work is a problem for the people living in such areas, especially for frail elderly people, disabled person with no support from their family. One solution for the problem, snow removal volunteer tours mediating cross-regional and cross-generational exchanges between urban areas and people living in depopulated heavy snowfall areas become popular in recent years (Hara, 2018).

The strenuous nature of manual snow shoveling work has been well documented in preceding papers. However, the degree of difficulty in snow shoveling strongly depend on situations. Konishi et al. (2012) reported that the level of activities of daily living (ADL) of residents in heavy snowfall regions is one of the determinants of snow removal ability. Even if snow is fresh and soft snow, snow removal work from the house entrance to the road, called "Maguchi josetsu" in Japanese is demanding activity for frail people. While snow removal work from other residential space such as under the windows, snow on the roof of the garage, called "Iemawari josetsu" and because of hard and heavy conditions were performed with higher ADL scores.

Most of the previous studies on physiological responses to snow shoveling work were performed using an experimentally designed model. The conditions in these studies were single layer of fresh snow or artificially homogenized snow (Smolander et al., 1995), shallow depth of snow, and short work time (Table 1). Moreover, there is little information on the workload of intensive snow shoveling performed in actual situations. In a snow removal volunteer tour, participants are required to spend a long time to clear away large amounts of heavy snow around houses.

The workload for clearing snow is greatly affected 
Table 1. Characteristics of snow conditions, work time and metabolic equivalent (MET) in previous studies on physiological responses to snow removal.

Experimental studies

\begin{tabular}{|c|c|c|c|c|c|}
\hline & $\begin{array}{c}\text { Snow } \\
\text { depth }(\mathrm{cm})\end{array}$ & $\begin{array}{l}\text { Snow density } \\
\qquad\left(\mathrm{g} \mathrm{cm}^{-3}\right)\end{array}$ & Snow condition & $\begin{array}{l}\text { Work time } \\
\text { (min) }\end{array}$ & Subjects, MET \\
\hline Suda et al. 1990 & $40-70$ & 0.2 & No data & 10 & 13 elderly males, 5.5 \\
\hline $\begin{array}{l}\text { Sheldahl et al. } \\
1992\end{array}$ & 7.6-10.2 & No data & No data & $\begin{array}{c}8 \min \times 3 \\
\text { types }\end{array}$ & $\begin{array}{l}4 \text { males with coronary } \\
\text { artery disease, } 5.4\end{array}$ \\
\hline $\begin{array}{l}\text { Smolander et al. } \\
1995\end{array}$ & $40-60$ & $0.309 \pm 19$ & $\begin{array}{l}\text { Hard snow and soft } \\
\text { snow }\end{array}$ & 15 & 9 males, 7.9 \\
\hline $\begin{array}{l}\text { Franklin et al. } \\
1995\end{array}$ & $7.6-12.7$ & No data & Heavy wet snow & 10 & 32 males, 5.7 \\
\hline $\begin{array}{l}\text { Yamashita et al. } \\
2003\end{array}$ & $30-50$ & $\begin{array}{l}0.40 \\
(0.22-0.55)\end{array}$ & $\begin{array}{l}\text { Fresh snow and } \\
\text { depth hoar }\end{array}$ & 5 & $\begin{array}{l}12 \text { young males and } \\
\text { females, } 6.9\end{array}$ \\
\hline & & & & & $\begin{array}{l}11 \text { middle-aged and } \\
\text { elderly males, } 6.4\end{array}$ \\
\hline $\begin{array}{l}\text { Morita et al } \\
2006\end{array}$ & 40 & $0.32 \pm 0.1$ & Hard crust snow & 10 & $\begin{array}{l}8 \text { elderly males, } 8.2 \\
5 \text { elderly females, } 6.6\end{array}$ \\
\hline Field study & & & & & \\
\hline $\begin{array}{l}\text { Konishi et al. } \\
2012\end{array}$ & No data & $0.18-0.37$ & No data & 20 & $\begin{array}{l}4 \text { students, } 6.0,3 \text { elderly } \\
\text { males and one female, } 5.6\end{array}$ \\
\hline
\end{tabular}

by the characteristics of the snow (Smolander et al., 1995). In addition, there has been no information on the nature of snow in actual living conditions.

The purpose of this study was to elucidate the characteristics of physiological responses to intensive snow shoveling work under severe snow conditions performed by participants of a snow removal volunteer tour in an area with heavy snowfall.

\section{Methods}

\subsection{Subjects}

The subjects of this study were six healthy males (mean age \pm standard error, $50 \pm 8$ years). They were participants of a volunteer tour from Sapporo to help frail people living in Miruto area, a depopulated area with heavy snowfall. None of the subjects had a functional disorder or cardiovascular disease. All subjects gave informed written consent for participation in this study after receiving a complete written explanation of the purpose of the investigation and the proposed measures. The ethical protocol for this study was approved by the Ethics Committee for Human Investigation of the Graduate School of Education in Hokkaido University.

Table 2 shows the physical characteristics of the subjects. The maximum heart rate $\left(\mathrm{HR}_{\max }\right)$ is the highest
HR achieved in an all-out effort to the point of volitional fatigue. Since direct measurement of $\mathrm{HR}_{\max }$ needs medical attention, $\mathrm{HR}_{\max }$ is often estimated on the bases of age because $\mathrm{HR}_{\max }$ shows a slight predictable decrease of about one beat per year beginning at 10 to 15 years of age. Subtracting age from 220 beats $\mathrm{min}^{-1}$ provides a reasonable approximation of predicted $\mathrm{HR}_{\max }$ (Kenney et al., 2015).

\subsection{Indirect measurement of oxygen consumption $\left(\mathrm{VO}_{2}\right)$ for fieldwork}

A portable respiratory gas analyzer was used in previous studies (Franklin et al., 1995; Smolander et al., 1995; Yamashita et al., 2003; Morita et al., 2006) for the direct measurement of the volume of oxygen consumption $\left(\dot{\mathrm{VO}}_{2}\right)$ during snow shoveling (Fig. la and Fig. 1b). However, direct measurement of $\mathrm{VO}_{2}$ requires expensive instruments and skilled technician. Because of the costs associated with equipment, space, and personnel, direct measurement of $\mathrm{VO}_{2}$ is generally carried out only for experimental research (American college of sports medicine (ACSM), 2000). This method is not suitable for field measurements when several subjects are performing intensive snow shoveling at the same time in a confined space for a long period of time. When direct measurement of $\dot{\mathrm{VO}}_{2}$ is not feasible or desirable, a multistage 
Table 2. Physical characteristics of the subjects.

\begin{tabular}{cccccc}
\hline Subject & $\begin{array}{c}\text { Age } \\
\text { (years) }\end{array}$ & $\begin{array}{c}\text { Height } \\
(\mathrm{cm})\end{array}$ & $\begin{array}{c}\text { Weight } \\
(\mathrm{kg})\end{array}$ & $\begin{array}{c}\dot{\mathrm{VO}_{2 \max }} \\
\left(\mathrm{ml} \mathrm{kg}^{-1} \mathrm{~min}^{-1}\right)\end{array}$ & $\begin{array}{c}\text { Predicted } \mathrm{HR}_{\max } \\
\left(\text { beats } \min ^{-1}\right)\end{array}$ \\
\hline A, Male & 51 & 174 & 64 & 35.6 & 169 \\
B, Male & 64 & 160 & 62 & 30.3 & 156 \\
C, Male & 59 & 173 & 64 & 39.5 & 161 \\
D, Male & 71 & 163 & 64 & 35.1 & 149 \\
E, Male & 30 & 173 & 71 & 27.3 & 190 \\
F, Male & 25 & 173 & 79 & 38.3 & 196 \\
\hline Mean \pm SE & $50 \pm 8$ & $169 \pm 2.5$ & $67.3 \pm 2.7$ & $34.4 \pm 1.9$ & $170.7 \pm 7.8$ \\
\hline
\end{tabular}

(Predicted $\mathrm{HR}_{\max }$ was calculated by 220 -age)

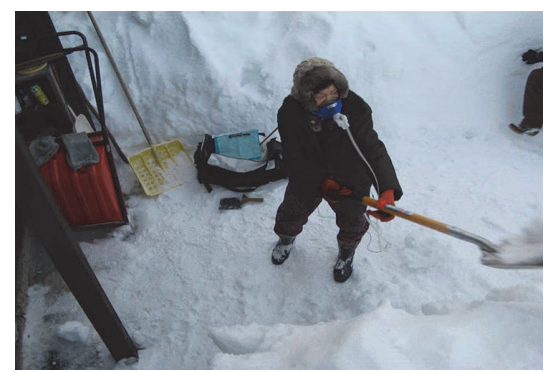

Fig. 1a

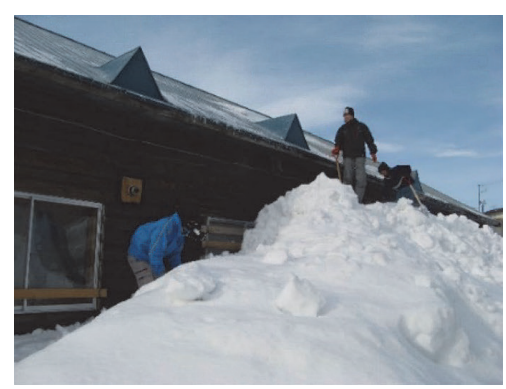

Fig. 1b

Fig. 1. Measurements of cardiorespiratory responses to snow shoveling using a portable expiratory gas analyzer in two subjects. An 86-years-old female is performing fresh snow removal from an entrance to the driveway, called "Maguchi-josetsu" (Fig. 1a). A 26-year-old male (left) is engaging in co-operative snow shoveling under eaves. This type of intensive snow removal is called "Ie-mawari josetu" (Fig. 1b).

cycle ergometer (MSCE) test can be used to estimate $\mathrm{VO}_{2}$. This test has been validated by examining the correlation between directly measured $\mathrm{VO}_{2}$ and estimated $\dot{\mathrm{VO}}_{2}$ from physiologic responses to heart rate at a specified power output (watt). The results of an MCSE test provide a reasonably accurate indication of an individual's fitness at a low cost and in a short time with little effort required by the subject. Estimated gross oxygen $\left(\dot{\mathrm{V}}_{2}, \mathrm{ml} \mathrm{kg}^{-1} \mathrm{~min}^{-1}\right)$ was calculated from the following metabolic equation described as ACSM (2000);

$$
\dot{\mathrm{VO}}_{2}=\{(10.8 \times W) / M\}+7.0
$$

where $M$ is body mass $(\mathrm{kg})$ and $W$ is work rate (power in watts).

It is well known that the heart rate and $\mathrm{VO}_{2}$ shows linear relationship during exercise and that $\mathrm{VO}_{2}$ and heart rate also increase linearly with increase in work load expressed as work rate (power in watts) in the case of cycle ergometer test (Kenney et al., 2015). We decided that the relationship can be applied to estimate the volume of oxygen consumption $\left(\mathrm{V}_{2}\right)$ and energy expenditure from heart rate during snow shoveling in an actual field site as a substitute for direct measurement.

\subsection{Laboratory measurements}

Before conducting field measurements, the subjects were asked to participate in two laboratory tests. Each subject performed MSCE test until near exhaustion for determination of maximum oxygen consumption $\left(\dot{\mathrm{VO}}_{2 \max }\right)$ and to determine the relationship between heart rate and $\dot{\mathrm{VO}}_{2}$ (Test 1).

Most of the exercises prescribed for health promotion involve the use of large muscle groups (leg muscles) over prolonged periods of activities that are rhythmic and aerobic in nature (e.g., walking, jogging, running, swimming, and cycling) as prescribed by ACSM (2000). In these activities, most of the energy is used for locomotion of the exerciser. On the other hand, snow shoveling involves small muscles (arm muscles) and a large amount of energy is expended by removal motion (digging, cutting out the snow, lifting and throwing) of the external load (shovel and snow mass), and the component of locomotion of exerciser is therefore relatively small. It is necessary to determine whether the relationship between heart rate and $\mathrm{VO}_{2}$ in a cycle ergometer test is appropriate for that in snow shoveling work.

A multistage shoveling test was also carried out (Test 2, Fig. 2). The test involved scooping a sandbag from the floor and throwing it to a marker on a wooden chute positioned at $1.0 \mathrm{~m}$ in height and a horizontal distance of $1.5 \mathrm{~m}$ from the toe line of the subject using a plastic snow shovel $(1.4 \mathrm{~kg}$ in weight, $0.76 \mathrm{~m}$ in shaft length, and $1344 \mathrm{~cm}^{2}$ in blade area, made by Sekisui Co., 
Japan). The shoveling load (weight of the sandbag) and the shoveling rate (paced by an audio tape) were increased every 4 minutes according to the protocol shown in Table 3.

Heart rate was measured using a heart rate monitor (S610i, made by Polar Electro Co, Finland). A portable expiratory gas analyzer (VO2000, made by Medical Graphics Co., USA) was used to measure respiratory

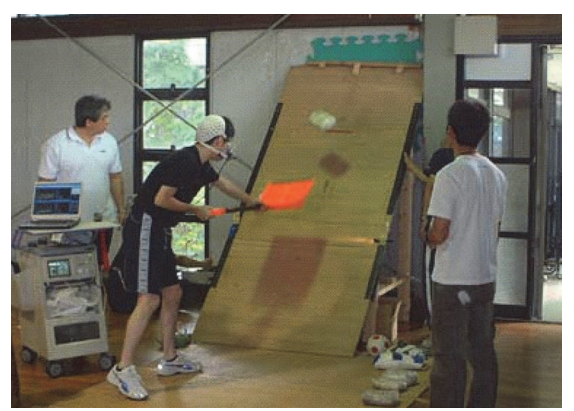

Fig. 2. Multistage shoveling test. The shoveling workload was expressed as the product of shoveling load $(\mathrm{kg})$ by shoveling rate (times $\mathrm{min}^{-1}$ ). variables in both experiments. The two laboratory tests were conducted within a 3-day period at similar times of day.

\subsection{Measurements of snow conditions}

Before field measurements of the physiological responses to snow shoveling work, measurements of snow conditions of the work sites were carried out on February 2, 2014 in Miruto area, located $15 \mathrm{~km}$ east from center of Iwamizawa City in Hokkaido, Japan. This area is categorized as a "special heavy snowfall region".

Table 4 shows measured parameters and the instruments in this study. Snow conditions (particle shape, density and hardness) of each layer were measured at two vertical snow walls (I and II) in front of the detached house shown in Fig. 3. The snow observations followed the methodology outlined by the Japanese Society of Snow and Ice (1991). In the experiment day, weather was fine and breeze. Mean air temperature were $-6.3{ }^{\circ} \mathrm{C}$ at starting time in the morning and $-1.4{ }^{\circ} \mathrm{C}$ at the ending time in the afternoon. The snow depth at the worksites were $162 \mathrm{~cm}$ and $173 \mathrm{~cm}$ for site I and site II, respec-

Table 3. Protocol of the multistage shoveling test.

\begin{tabular}{|c|c|c|c|c|c|c|c|c|c|}
\hline Stage & 1 & 2 & 3 & 4 & 5 & 6 & 7 & 8 & 9 \\
\hline Duration (min) & 4 & 4 & 4 & 4 & 4 & 4 & 4 & 4 & 4 \\
\hline Shoveling load (kg) & 3 & 3 & 5 & 5 & 8 & 8 & 8 & 8 & 8 \\
\hline Shoveling rate (time $\min ^{-1}$ ) & 10 & 15 & 12 & 15 & 12 & 15 & 18 & 21 & 24 \\
\hline Work rate $\left(\mathrm{kg} \mathrm{min}^{-1}\right)$ & 30 & 45 & 60 & 75 & 96 & 120 & 144 & 168 & 192 \\
\hline
\end{tabular}

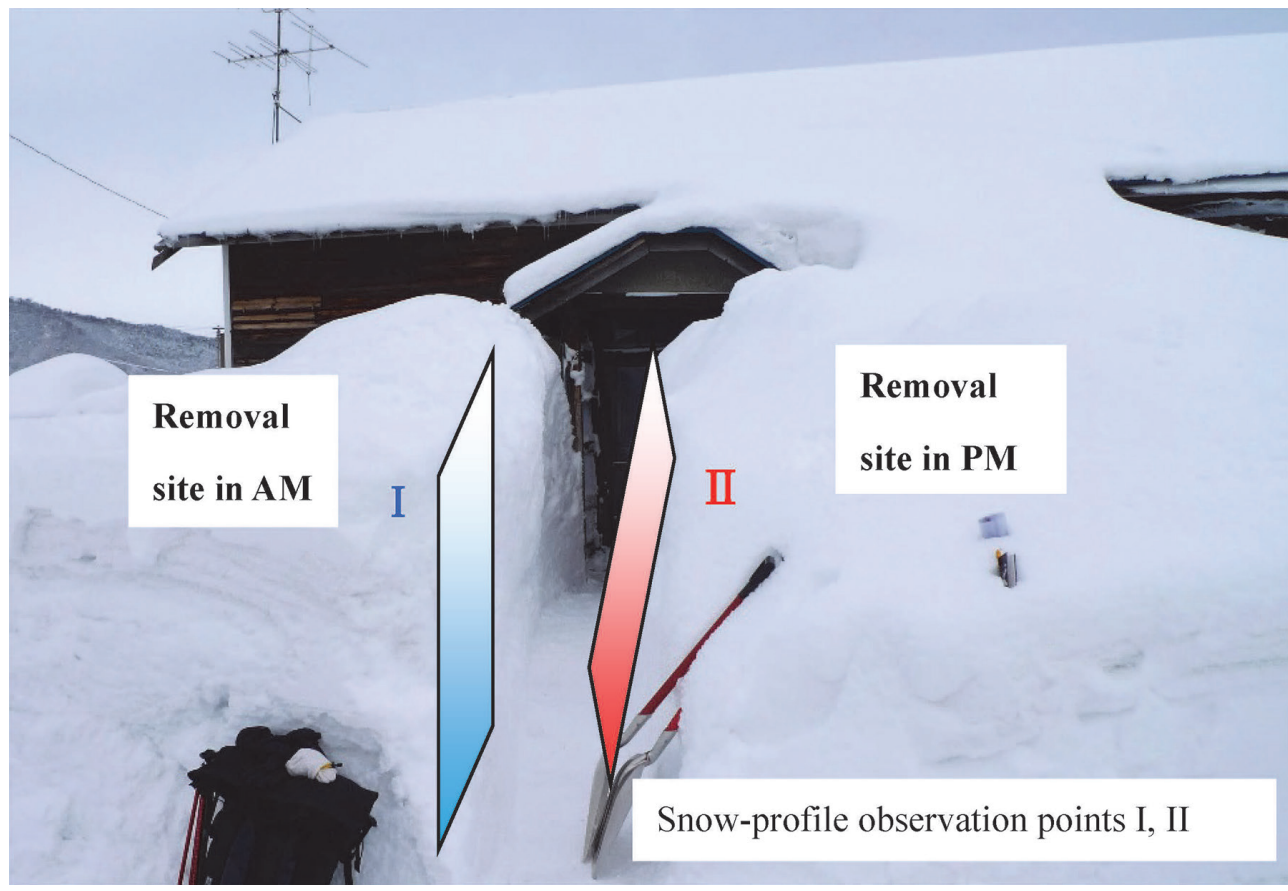

Fig. 3. Measured point of snow conditions in the snow shoveling work site. Facing the entrance, the subjects engaged in snow shoveling on the left side (I) in the morning (AM) and on the right side (II) in the afternoon (PM). 
Table 4. Measurements of snow conditions.

\begin{tabular}{ll}
\hline Parameter & Instrument \\
\hline Air temperature, snow temperature & $\begin{array}{l}\text { Thermistor thermometer } \\
\text { Keight of snow cover }\end{array}$ \\
\hline Snow profile & \\
Snow depth & Snow sonde \\
Snow density & Cuboid type density sampler \\
Snow hardness & Snow-hardness meter \\
Pit-wall observation & Visual observation \\
\hline
\end{tabular}

tively.

\subsection{Field measurements of physiological responses to snow shoveling}

The subjects were asked to dispose of snow that had accumulated under the eaves of the roof of a singlestoried house. The snow was removed to prevent window panels being broken by snow falling from the roof and to allow sunlight into rooms so that residents would not become depressed. All subjects engaged in self-paced snow shoveling across the lunch time. Mean total work time including a break for a few minutes was $111 \pm 3 \mathrm{~min}$. The subjects wore the same clothing and rubber boots that they usually wore for snow shoveling work. Three types of shovel were used depending on the snow hardness and snow density. Weight, shaft length and blade area were $1.8 \mathrm{~kg}, 66 \mathrm{~cm}$ and, $1200 \mathrm{~cm}^{2}$ for the aluminum shovel, $2.0 \mathrm{~kg}, 70 \mathrm{~cm}$ and $700 \mathrm{~cm}^{2}$ for the square point steel shovel, and $1.9 \mathrm{~kg}, 68 \mathrm{~cm}$ and $588 \mathrm{~cm}^{2}$ for the spade-shaped shovel, respectively. Heart rate was recorded from the heart rate monitor. Rating of perceived exertion (RPE) was assessed at the end of each session of work using the Borg 6-20-point scale (Borg, 1970).

\subsection{Statistical analysis}

The paired t-test was used to determine significant differences between mean values in the morning and in the afternoon. Relationships between variables of interest were determined by using Pearson's correlation coefficient test, simple regression analysis and polynomial approximation. Differences were considered significant if $\mathrm{p}<0.05$.

\section{Results}

\subsection{Snow conditions of the working site}

Figure 4 shows the snow condition data of the work site. The dashed green line shows the snow height line after snow removal in the morning $(75 \mathrm{~cm})$ and the dashed red line shows the snow height after snow removal in the afternoon $(92 \mathrm{~cm})$. As shown in the stratigraphy, snow particle shape of the layer in the morning and afternoon were almost the same. Figure 5 shows the relationships among snow hardness (lower scale), snow density (upper scale) and removed snow depth (vertical scale) in the morning and afternoon. Snow density and snow hardness increased from a snow depth of $100 \mathrm{~cm}$ to $60 \mathrm{~cm}$. Snow density increased linearly with increase in snow depth in the morning and afternoon. On the other hand, snow hardness (lower scale) increased exponentially from surface to a snow depth of $60 \mathrm{~cm}$. These characteristics of snow around a detached house were not mentioned in previous reports.

3.2 Relationships between heart rate and $\mathrm{VO}_{2}$ in the cycle ergometer test (Test 1) and the multistage shoveling test (Test 2)

Figure 6 shows the relationship between the estimated values of volume of oxygen consumption (x) and the values of volume of oxygen consumption (y) measured by a portable expiratory gas analyzer during cycle ergometer test (Test 1 ) in the six subjects. The mean correlation coefficients between estimated and measured $\dot{\mathrm{VO}}_{2}$ is $0.927(\mathrm{~N}=47, \mathrm{p}<0.001)$. With the exception of subject $B$, the regression coefficients in the subjects ranged close to 1.0 .

Figure 7 shows the relationship between shoveling work rate $(\mathrm{x})$, expressed as shoveling load $(\mathrm{kg})$ by shoveling rate (times $\min ^{-1}$ ), and $\dot{\mathrm{VO}}_{2}$ (y) in the multistage shoveling test. Correlation coefficients of individual values ranged from 0.939 to 0.994 , and the total value was 0.866 $(\mathrm{N}=37, \mathrm{p}<0.001)$. The relationship between heart rate and $\dot{\mathrm{VO}}_{2}$ was linear in both the cycle ergometer test $(\mathrm{p}<$ $0.001)$ and the multistage shoveling test $(\mathrm{p}<0.001) . \dot{\mathrm{VO}}_{2}$ increased linearly with increase in workload for all subjects. Although $\dot{\mathrm{VO}}_{2}$ increased linearly with increase in shoveling workload, $\dot{\mathrm{VO}}_{2}$ at a given workload showed a large variance due to the individual differences in regression slope. Therefore, the regression equation from total data for shoveling work rate are not appropriate for estimation of $\dot{\mathrm{VO}}_{2}$ or energy expenditure.

\subsection{Regression lines between $\mathrm{VO}_{2}$ and heart rate}

Figure 8 shows the regression lines of $\dot{\mathrm{VO}}_{2}(\mathrm{x})$ and heart rate $(\mathrm{y})$ in the multistage cycle ergometer test ( Test 1 ) and in the multistage shoveling test ( $\bigcirc$, Test 2). The plotted data shows the mean values of heart rate in the six subjects against $\dot{\mathrm{VO}}_{2}$. Both in Test 1 and Test 2, 


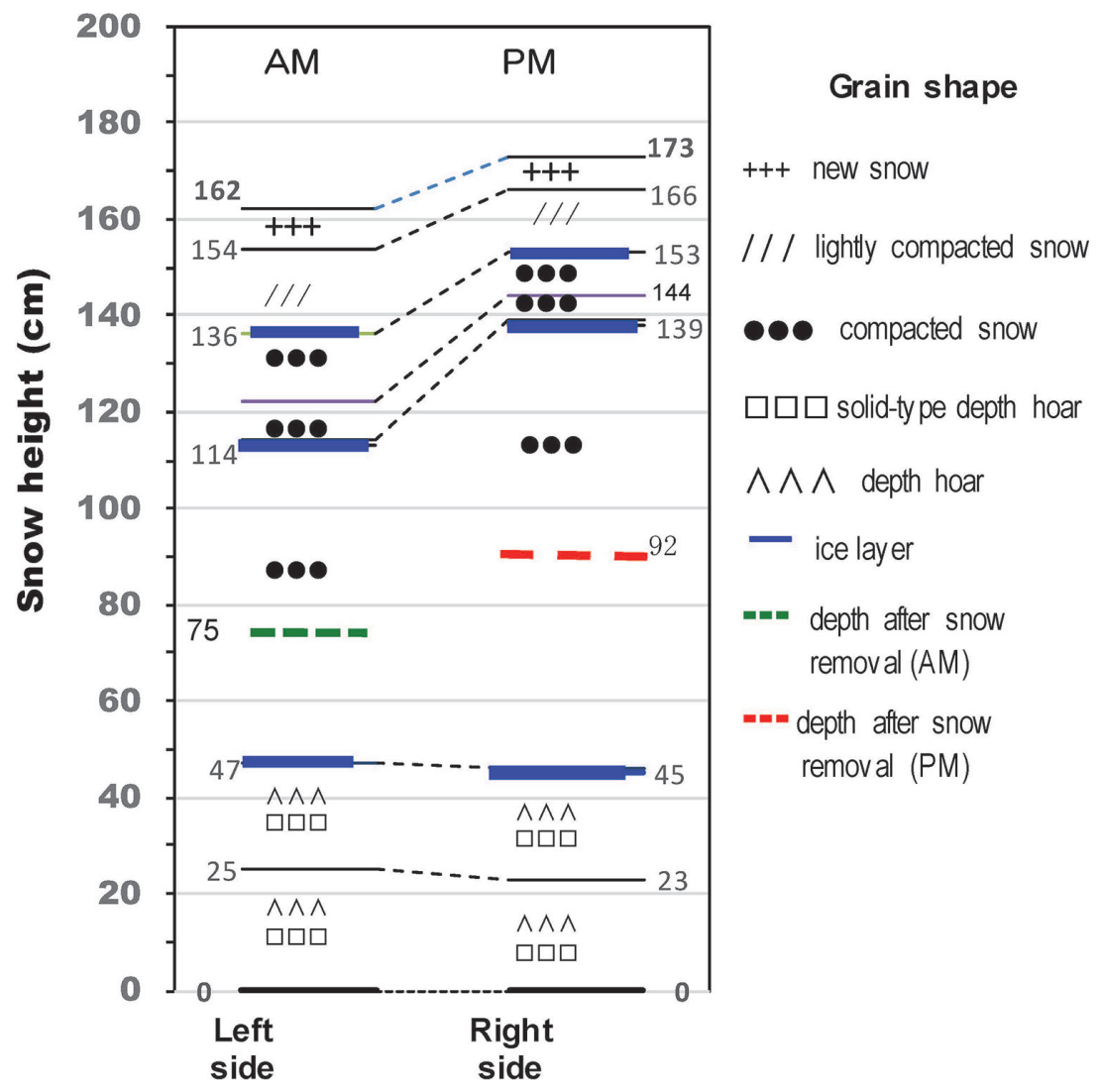

Fig. 4. Snow particle shapes of snow removal work site.

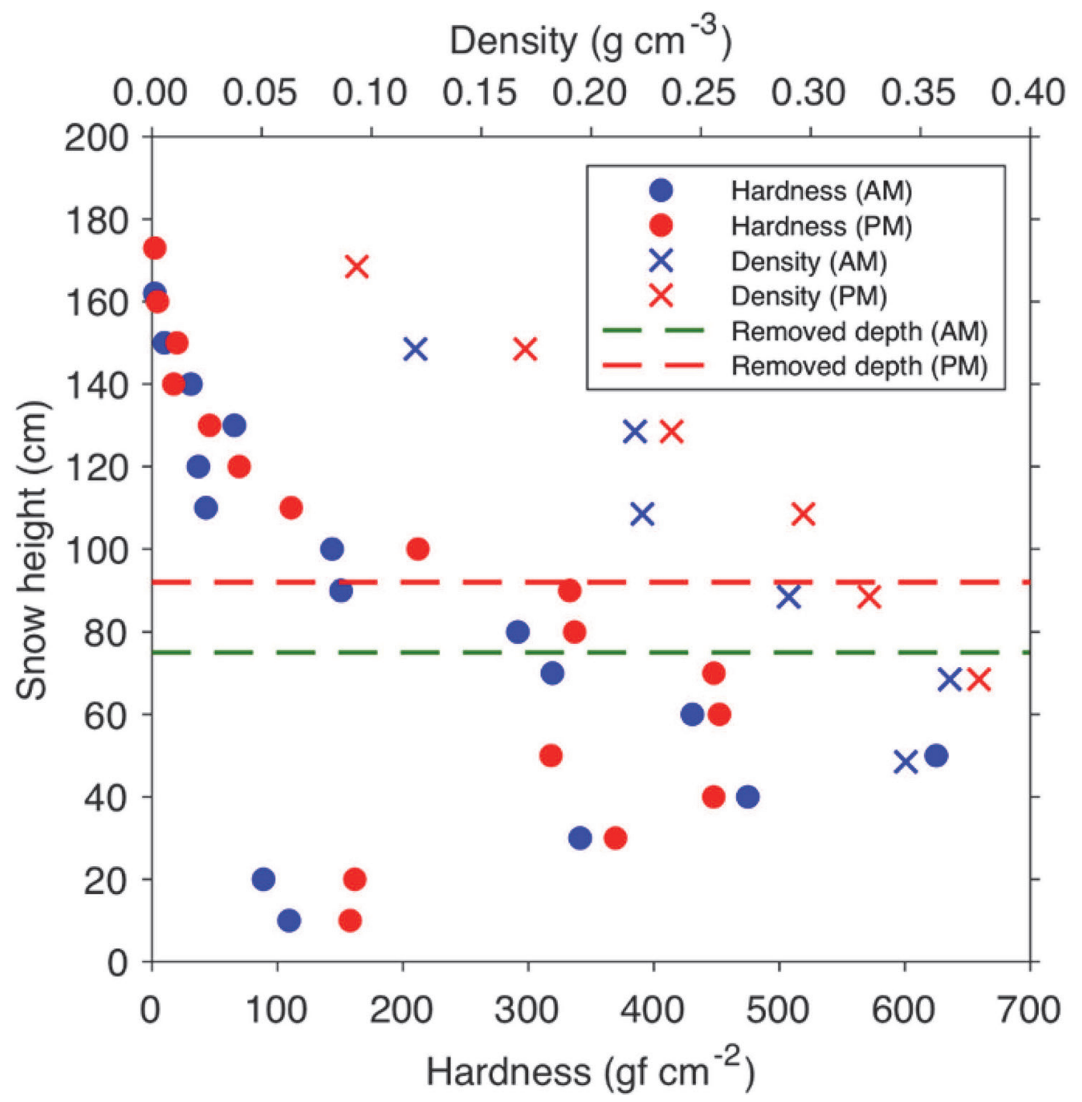

Fig. 5. Relationships among snow density (upper horizontal axis) and hardness (lower horizontal axis) from the snow surface to the ground in the work site (vertical axis). 


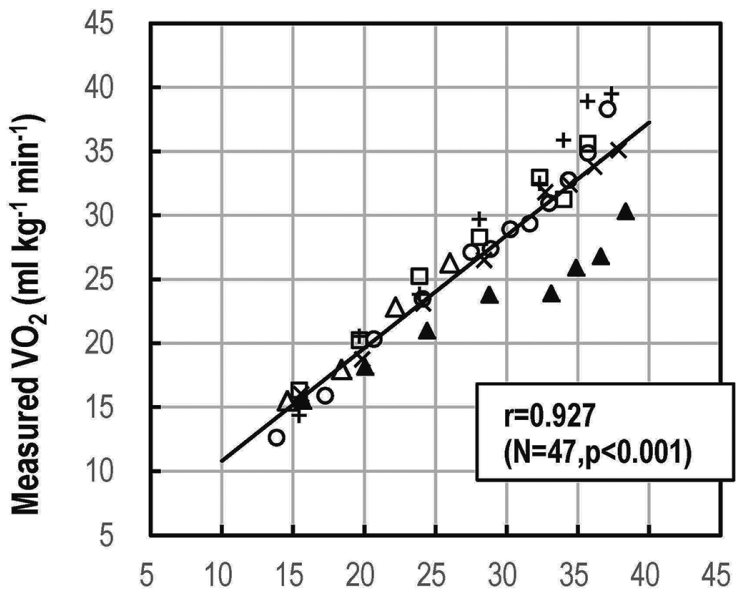

Estimated $\mathrm{VO}_{2}\left(\mathrm{ml} \mathrm{kg}^{-1} \mathrm{~min}^{-1}\right)$

\begin{tabular}{|l|c|l|}
\hline Subj.age & $R$ & $\begin{array}{l}\text { Regression } \\
\text { equation }\end{array}$ \\
\hline$\square A, 51$ yrs. & 0.987 & $Y=0.90 x+2.82$ \\
\hline$\Delta$ B,64yrs. & 0.976 & $Y=0.57 x+6.65$ \\
\hline$+C, 59$ yrs. & 0.976 & $Y=1.14 x-2.73$ \\
\hline$\times D, 71$ yrs. & 0.997 & $Y=0.89 x+1.62$ \\
\hline$\Delta E, 30$ yrs. & 0.993 & $Y=0.98 x+0.77$ \\
\hline$\bigcirc F, 25$ yrs. & 0.993 & $Y=1.01 x-1.35$ \\
\hline
\end{tabular}

$-y=x$

Fig. 6. Relationship between estimated $\dot{\mathrm{V}}_{2}(\mathrm{x})$ and measured $\dot{\mathrm{V}}_{2}$ (y). Measured $\dot{\mathrm{VO}}_{2}$ was obtained from a respiratory gas analyzer during the cycle ergometer test (Test 1$)$.

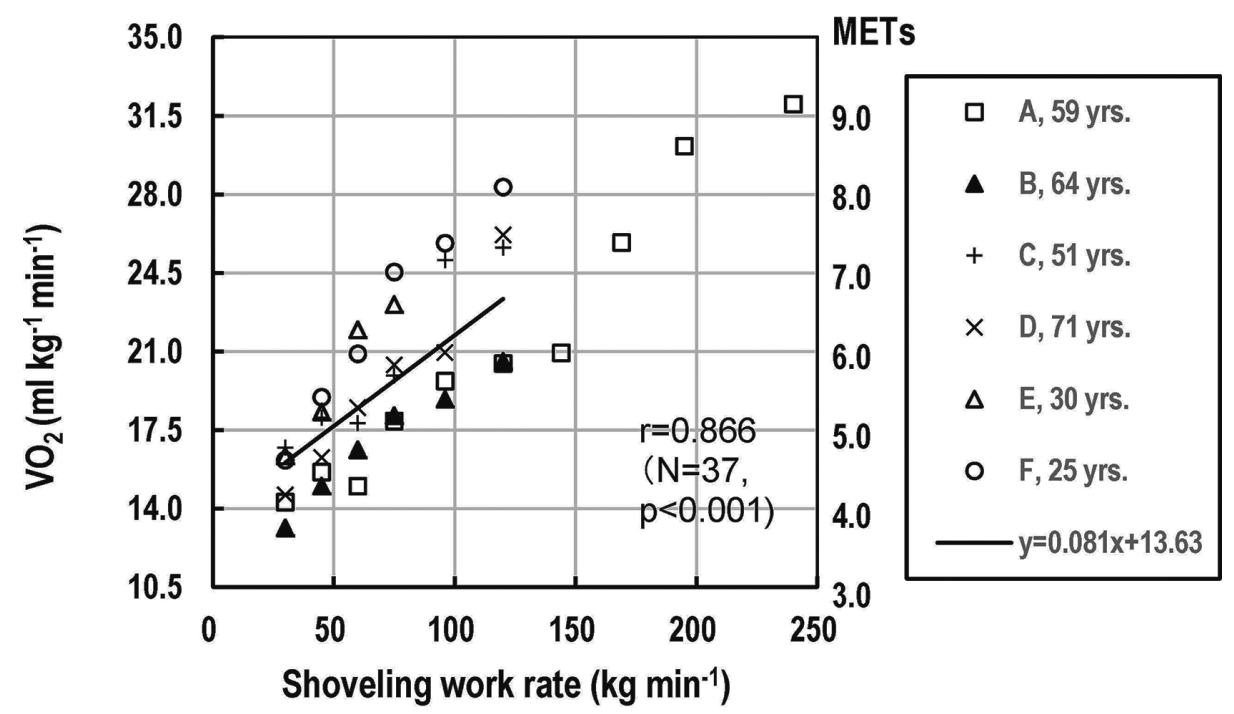

Fig. 7. Relationship between shoveling work rate (x) expressed as shoveling load (kg) $\times$ shoveling rate (scoops $\min ^{-1}$ ) and oxygen uptake $\left(\mathrm{y}, \dot{\mathrm{V}} \mathrm{O}_{2}, \mathrm{ml} \mathrm{kg}^{-1} \mathrm{~min}^{-1}\right.$ ). METs $=$ metabolic equivalents assuming a rest oxygen consumption of $3.5 \mathrm{ml} \mathrm{kg}^{-1} \mathrm{~min}^{-1}$.

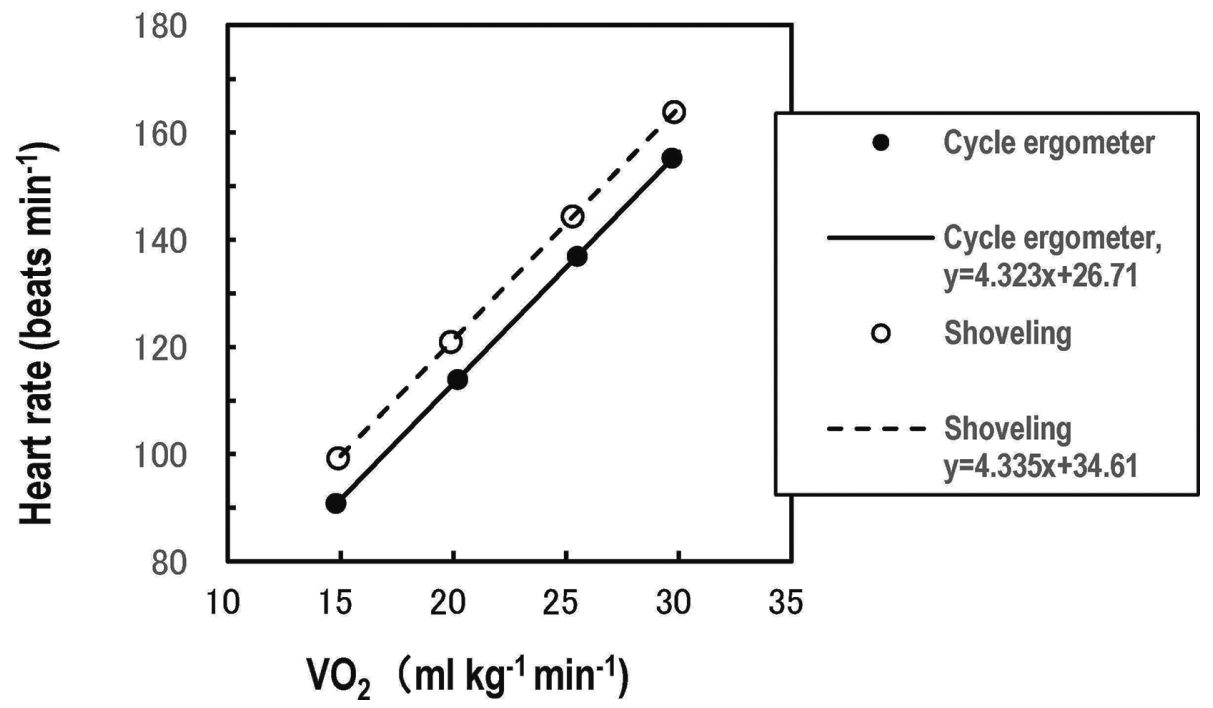

Fig. 8. Regression lines of heart rate $(\mathrm{x})$ and $\dot{\mathrm{V}}_{2}$ (y) during the cycle ergometer test and multistage shoveling test $(\bigcirc$, Test 2$)$. 


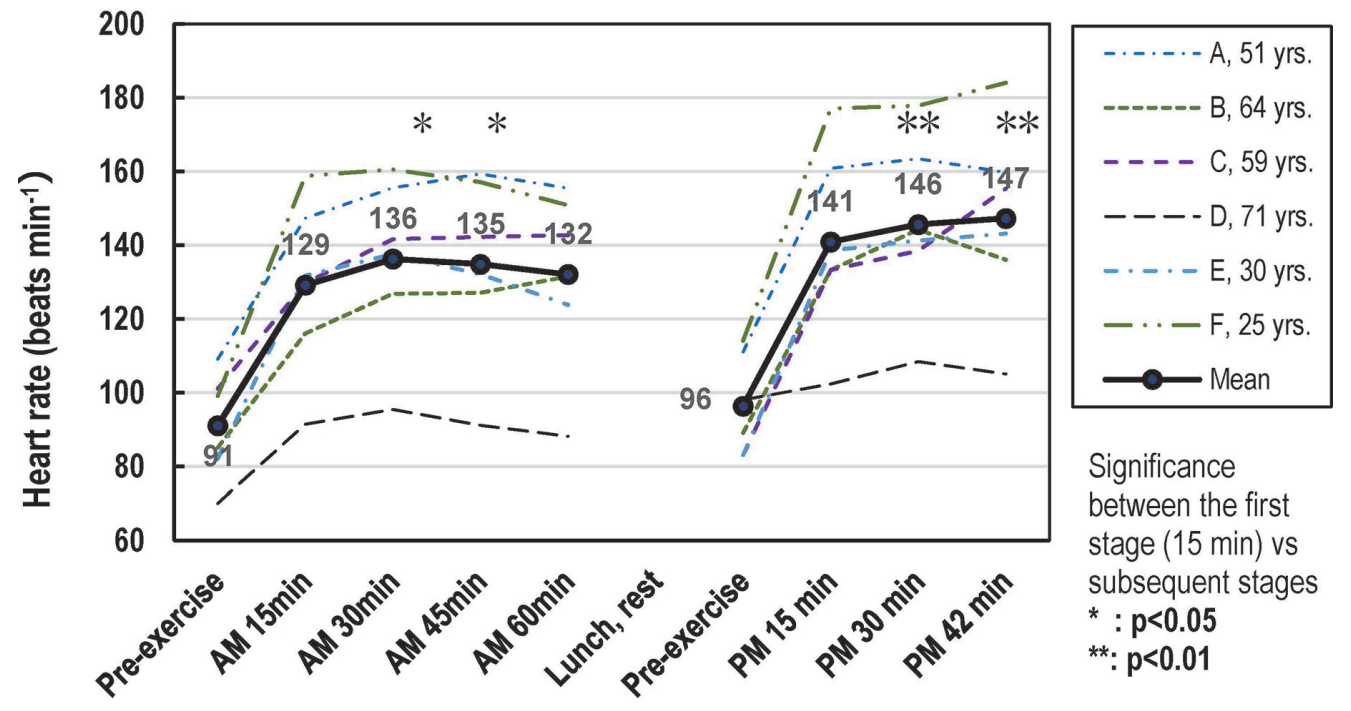

Fig. 9. Changes in mean heart rate (black circles) and individual values (dotted lines) of snow shoveling during work periods of morning and afternoon.

the regression lines of $\dot{\mathrm{V}}_{2}$ and heart rate are parallel within a wide range. Regression coefficients were nearly equal (0.432 and 0.434). Constant terms in Test 2 were 6 to 8 beats $\mathrm{min}^{-1}$, which are higher than those in Test 1 . These findings suggest that $\dot{\mathrm{V}}_{2}$ and energy expenditure at a given heart rate will be slightly lower in shoveling work than in a cycle ergometer work. In consideration of these results, $\dot{\mathrm{V}}_{2}$ or metabolic equivalent (MET) of task during field measurement was calculated using the regression equation with each individual by Test 2 .

Caloric expenditure $\left(\mathrm{kcal} \mathrm{min}^{-1}\right)$ was estimated from the following equation (ACSM, 2000);

$$
\begin{aligned}
& \text { Caloric expenditure }\left(\mathrm{kcal} \mathrm{min}^{-1}\right) \\
& \quad=(\text { METs } \times 3.5 \times \text { body weight }) / 200 .
\end{aligned}
$$

The averaged value of estimated $\dot{\mathrm{V}}_{2}$ in snow shoveling during the total work period was $22.2 \pm 1.2 \mathrm{ml} \mathrm{kg}^{-1} \mathrm{~min}^{-1}$ $(\mathrm{MET}=6.4 \pm 0.3)$. The total energy expenditure was estimated $782 \pm 46 \mathrm{kcal}$.

\subsection{Physiological responses to snow shoveling}

Figure 9 shows changes in mean heart rate every 15 minutes during snow shoveling in the work periods in the morning and afternoon. Mean work periods in the morning and afternoon were 64 and 47 minutes, respectively, and mean total work time was $111 \pm 3$ minutes. A large individual difference was observed in heart rate. The youngest subject $\mathrm{F}$ (25 years) showed the highest line in figure. The oldest subject D (71 years) showed the lowest line in figure. These differences are thought to be due to the decline of $\mathrm{HR}_{\max }$ with advance of age and individual variability of heart rate response. The mean heart rate during the work period in the afternoon (142 \pm 9 beats $\left.\mathrm{min}^{-1}\right)$ was significantly $(\mathrm{p}<0.01)$ higher than that in the morning $\left(131 \pm 9\right.$ beats $\left.\mathrm{min}^{-1}\right)$. These heart rate correspond to $84 \%$ and $77 \%$ of the predicted values of maximum heart rate $\left(\mathrm{HR}_{\max }\right)$.
Both periods of time in the morning and afternoon, the mean heart rate in the first 15 minutes of work was significantly lower than the mean heart rates in subsequent stages. Estimated $\dot{\mathrm{V}}_{2}$ in the total work period averaged $22.2 \pm 1.2 \mathrm{ml} \mathrm{kg}^{-1} \mathrm{~min}^{-1}$, and $6.4 \pm 0.3 \mathrm{METs}$ in terms of metabolic equivalent. Rating of perceived exertion (RPE) was not significantly different in the morning $(12.9 \pm 0.4)$ and afternoon $(12.4 \pm 0.3)$ as shown in Fig. 10. These values correspond to the "somewhat hard" $(\mathrm{RPE}=13)$ in the sensation category scale proposed by Borg (1970). Individual values ranged from 11 ("fairly light") to 15 ("hard"). The values tended to increase from the onset stage to subsequent stages in both periods both in the morning $(\mathrm{p}<0.01)$ and afternoon $(\mathrm{p}<0.05)$. This trend was similar to that for heart rate shown in Fig. 9.

\section{Discussion}

\subsection{Usefulness of the cycle ergometer test and the multistage shoveling test}

Our findings suggest that the cycle ergometer test may be useful for estimation of oxygen consumption without using an expensive expired gas analyzer and technical personnel (ACSM, 2000). However, it should be kept in mind that working muscles are limited mainly to large muscles (leg muscles) in cycle ergometer exercise. When the exercise is performed with the arms, the heart rate at a given oxygen consumption is higher than that when the exercise is performed with the legs (Vokac et al., 1975).

The maximal oxygen consumption in arm exercise is about $70 \%$ of that in leg exercise, and heavy exercise with the arms (such as digging and shoveling snow) may therefore be hazardous for patients with heart disease and completely untrained older individuals (Åstrand and Rodahl., 1986).

Smolander et al. (1995) reported that snow shoveling 


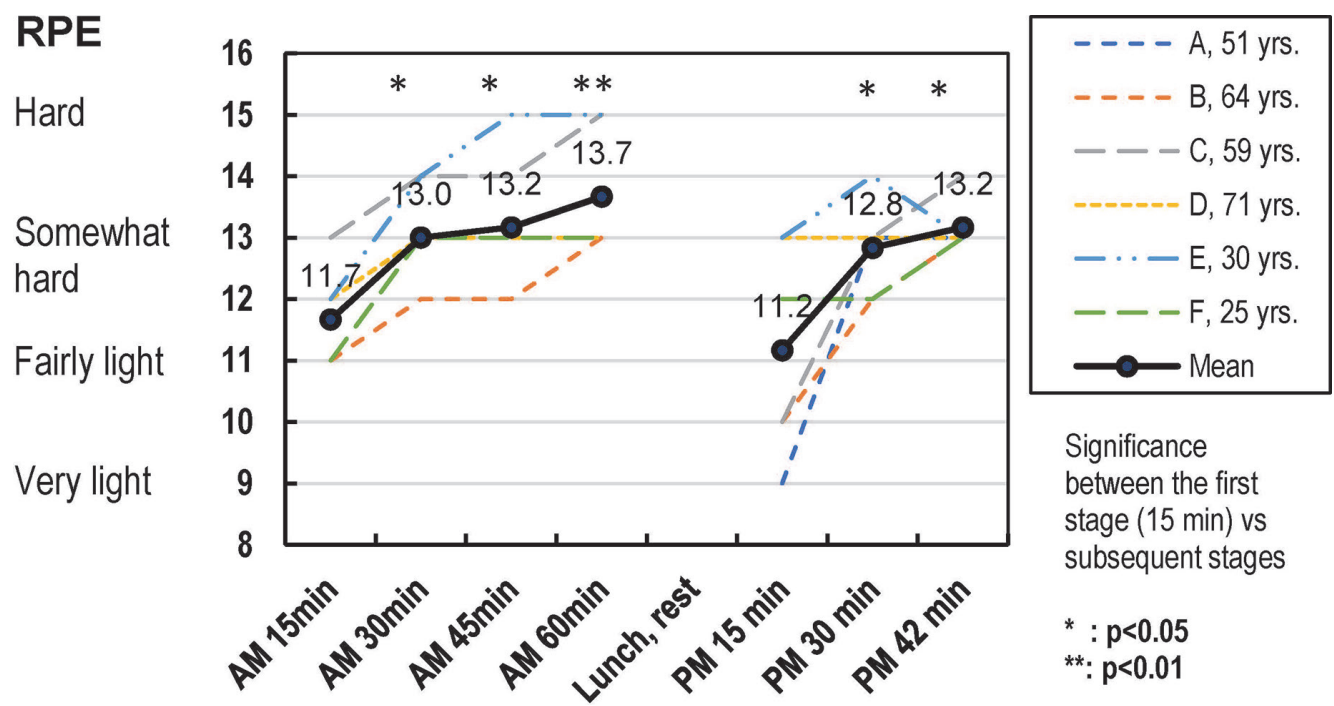

Fig. 10. Changes in rating of perceived exertion (RPE) during the work periods. Black circles and solid lines show the mean values of the 6 subjects.

was associated with a higher $\mathrm{HR}$ in relation to $\dot{\mathrm{VO}}_{2}$ than was snow pushing possibly due to the difference in active muscle mass. They explained that the work was relatively stationary during snow shoveling, for which upper body muscles are used. In contrast to snow shoveling, snow pushing was more dynamic, involving large muscle groups of the legs and trunk. These findings suggest that the participants in intensive snow removal tours should keep in mind the severity of snow conditions of the work site and difference in the $\dot{\mathrm{VO}}_{2}$ /heart rate relationship depending on the type of work. Thus, participants who are not so fit are recommended to perform soft snow shoveling or snow pushing, and fitter participants should perform heavy and hard snow shoveling at their own pace.

\subsection{Differences in the heart rate and $\mathrm{VO}_{2}$ relationship determined by the cycle ergometer test and the shoveling test}

At a given level of $\mathrm{VO}_{2}$ work, it is well known that work with small muscle groups (arm muscles) cause a higher heart rate than does work with large muscle groups (leg muscles). Snow shoveling is a relatively stationary exercise in which mainly upper body muscles are used. Franklin et al. (1995) reported that the highest heart rates during snow shoveling, arm-ergometer and treadmill tests were comparable $(175,171$, and 179 beats $\mathrm{min}^{-1}$, respectively). Oxygen consumption in the snow shoveling was similar to that in the arm-ergometer test $(\mathrm{MET}=5.7$ and 6.3 ) but was lower than that in treadmill test $(\mathrm{MET}=9.3)$.

As shown in Fig. 8, regression coefficients of the cycle ergometer test and multistage shoveling test were nearly the same (4.32 and 4.34). On the other hand, the constant term in the shoveling test was about 8 beats $\min ^{-1}$ greater than the corresponding heart rate in the cycle ergometer test. In other words, $\dot{\mathrm{VO}}_{2}$ at a given heart rate during shoveling work is estimated to be $1.5 \mathrm{ml} \mathrm{kg}^{-1} \mathrm{~min}^{-1}(\mathrm{MET}=0.4)$ lower than the corresponding heart rate in cycle ergometer work. These findings suggest that estimated $\dot{\mathrm{V}}{ }_{2}$ from the heart rate during shoveling work shows a linear, parallel relationship but slightly lower than estimated $\mathrm{VO}_{2}$ from heart rate during the cycle ergometer test due to the difference in the types of exercise.

\subsection{Relationships between snow conditions and physio- logical responses}

The strain of clearing snow is greatly affected by the characteristics of the snow (Smolander et al., 1995). Shoveling light snow is safe and approximates the work intensity commonly prescribed for aerobic training (Sheldahl et al., 1992). On the other hand, heavy snow shoveling elicits myocardial and aerobic demand that rivals maximal exercise in sedentary men (Franklin et al., 1995). Shoveling wet or heavy snow has occasionally caused death in people with cardiovascular diseases (Karpovich and Sinning, 1971).

Despite these findings, to our knowledge, the differences of the snow conditions of intensive snow removal were not evaluated in previous studies. As shown in Fig. 5, linear increase in snow density and exponential increase in snow hardness were observed with increase in snow depth in the morning and afternoon. In both the morning and afternoon, in the first 15 minutes of work, the density of snow was low, and snow type was categorized to soft new snow or lightly compacted snow. In subsequent stages of work, the snow particle shape changed to compacted snow including an ice layer. Snow density and snow hardness increased with advance of snow removal. Under these snow conditions, workers would be forced to exert greater force for penetrating the blade into the snow, greater strength for scooping the heavier snow mass, and greater 


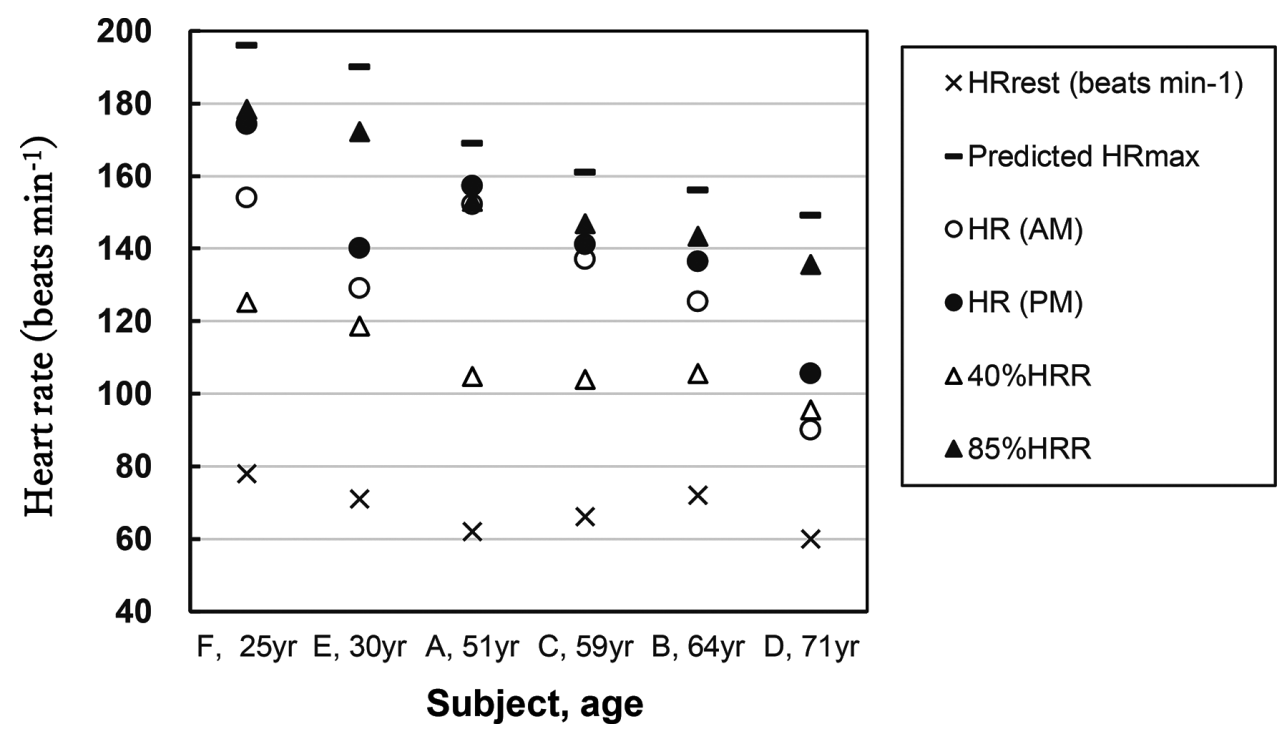

Fig. 11. Individual data of mean heart rate during intensive snow shoveling in the morning $(O)$ and afternoon ( ). $H_{\text {rest }}$ : resting H.R., predicted $H_{\text {max }}: 220$-age, $40 \% H R R=\left(\right.$ predicted $\left.H R_{\text {max }}-H_{\text {rest }}\right) \times 0.40+H R_{\text {rest }}$ $85 \% \mathrm{HRR}=\left(\right.$ predicted $\left.\mathrm{HR}_{\max }-\mathrm{HR}_{\text {rest }}\right) \times 0.85+\mathrm{HR}_{\text {rest }}$.

power for the throwing motion. These differences of the snow conditions were considered to effect on significant increase of heart rate and RPE from the first stage of work to subsequent stages both in the morning and afternoon.

\subsection{Physiological responses to intensive snow shoveling}

The American College of Sports Medicine (ACSM, 2000) recommends an intensity of aerobic exercise corresponding to between 55 and $65 \%$ (55/65\%) to $90 \%$ of maximum heart rate $\left(\mathrm{HR}_{\max }\right)$ or between 40 and $50 \%$ $(40 / 50 \%)$ to $85 \%$ of oxygen consumption reserve $\left(\dot{\mathrm{VO}}_{2} \mathrm{R}\right)$ or $\mathrm{HR}$ reserve (HRR). We consider $40 \%$ of $\mathrm{HRR}$ to be preferable to $50 \%$ of HRR since intensive manual snow removal activity demands a high cardiovascular load and prolonged work time than those for usual snow removal as a home activity. As shown in Fig. 11, the greater part of individual data distributed within the range from $40 \%$ of HRR to $85 \%$ of HRR as aerobic training zone.

Estimated $\dot{\mathrm{VO}}_{2}$ in the total work time ranged from 5.3 to 7.7 with an average of $6.4 \pm 0.3$ METs. These intensities are classified as a "moderate" or "vigorous" exercise intensity category. These values are comparable to competitive volleyball $(\mathrm{MET}=6.0)$, doubles tennis $(\mathrm{MET}=6.0)$, non-game basketball $(\mathrm{MET}=6.0)$ as sport activity, jogging (general, MET $=7.0$ ) or slow pace running ( $4 \mathrm{mph}, \mathrm{MET}=6.0$ ) as exercises, and weeding (cultivating garden, MET=5.0), mowing lawn $(\mathrm{MET}=5.5)$, digging (spading, filling, composing, $(\mathrm{MET}=7.8)$, shoveling snow $(\mathrm{MET}=6.0)$ as manual types of labor, exemplified from ACSM's "compendium of physical activities" reported by Ainthworth et al. (2011).

In our field study, the effects of other factors on physiological responses to intensive snow shoveling were not investigated. Further study is needed for issues that have not been investigated; (1) relationships of heat balance from heat production by intensive muscular activity with diet-induced thermogenesis (DIT) and heat loss in a cold environment, and (2) the relationships of fatigue with recovery period and blood pressure response to snow removal in elderly subjects.

\section{Conclusion}

The main findings obtained in this study were as follows.

1. Snow conditions of the work site changed to severe with time. Snow density and snow hardness increase from the start to end of work. The snow type changed from soft snow to light compacted snow and finally to compacted snow including an ice layer.

2. The exercise intensities in the morning time and afternoon time were $131 \pm 9$ and $142 \pm 9$ beats $\min ^{-1}$ ( $\mathrm{p}<$ 0.01 ), respectively in terms of heart rate and $12.9 \pm 0.4$ and $12.4 \pm 0.3$ (not significant), respectively in terms of RPE. The intensities were classified as "moderate" or "vigorous" in exercise intensity categories.

3. Estimated $\dot{\mathrm{VO}}_{2}$ values were $6.2 \pm 0.4$ METs in the morning and $6.9 \pm 0.3$ METs $(p<0.01)$ in the afternoon. Total $\dot{\mathrm{VO}}_{2}$ averaged $6.4 \pm 0.3 \mathrm{METs}$. These values were almost the same as those in previous experimentally designed investigations.

4. Considering that the participants in the present study engaged in vigorous work for long periods (64 min in the morning and $47 \mathrm{~min}$ in the afternoon, total of 111 min) under severe snow conditions, it is obvious that physical burdens for participants in a snow removal tour are not comparable to those in daily home activity. 


\section{Acknowledgments}

This work was supported in part by a grant from Hokkaido Development Association.

\section{References}

Ainthworth, B. E., Haskell, W.L., Hermann, S.D., Meckes, N., Basette, D.R., Tudor-Locke, C., Greer, J.L., Vezina, J., WhittGlover, M.C. and Leon, A.S. (2011): 2011 Compendium of Physical Activities: A Second Update of Codes and MET Values. Med. Sci. Sports Exercise, 43 (8): 1575-81. www.udg. edu/ca/Portals/59/OContent_Docs/2011_Compendium_ Tracking_Guide1.pdf, doi: 10.1249/mss.0b013e31821ece12.

Åstrand, P-O, and Rodahl, K. (1986): Textbook of Work Physiology. Third ed., McGraw-Hill Inc.192-193 pp.

American College of Sports Medicine (2000): ACSM's Guidelines for Exercise Testing and Prescription, Sixth Edition, Lippincott Williams \& Wilkins, Philadelphia, 95-312 pp.

Borg, G. (1970): Perceived exertion as an indicator of somatic stress. Scand J. Rehabil.Med., 2, 92-98.

Franklin, B. A., Hogan, P., Bonzeim, K. Bakalyar, D., Terren, E. Gordon, S. and Timmis, G. C. (1995): Cardiac demands of heavy snow shoveling. JAMA, J. Am. Med. Assoc., 15, 880882, doi: 10.1001/jama.273.11.880.

Hara, F. (2018): Snow removal in community and perspective of cross-regional snow removal volunteer activity. Ed. Kamimura, S., Tsutui, K., Numano, N. and Konishi, N., Snow removal in rural communities and the expansion of a volunteer snow removal service toward the future (in Japanese), Commons, 188-197 pp.

Japanese Society of Snow and Ice (1991): Measurement of snow and Ice. (in Japanese) Hokkaido University Publisher, 29$53 \mathrm{pp}$.

Karpovich, P.V. and Sinning, W. E. (1971): Physiology of muscular activity. $7^{\text {th }}$ ed. Philadelphia, W. B. Saunders, $138-140 \mathrm{pp}$

Kenney, W. L., Wilmore, J. H., and Costill, D. L. (2015): Physiology of Sport and Exercise sixth edition, Human Kinetics, Champaign, 196-197, 517-522 pp.

Konishi, N., Uenishi Y., Mizuno M., Suda T. (2012): Anthropological, Physiological Approach on Manual Snow Removal Performed by Community-Dwelling Elderly People and College Students. Proceedings of the $7^{\text {th }}$ International Conference on Snow Engineering, 132-147, Snow Engineering VII, Organizing Committee.

Morita I., Yamaguchi A., Yoshinari T., Hayashi M., Suda T. (2006): Differences in cardio-respiratory responses to snow shoveling and shovel performance between elderly males and females. Bull. Glaciol. Res., 23, 41-49.

Sheldahl, L. M., Wilke, N. A., Dougherty, S. M., Levandoski, S. G., Hoffman, M. D. and Tristiani, F. E. (1992): Effect of Age and Coronary Artery Disease on Response to Snow Shoveling. $J$. Am. Coll. Cardiol., 20, 1111-1117, doi: 10.1016/0735-1097 (92) 90366-u.

Sheldahl, L. M., Wilke, N. A., Dougherty, S. M. and Tristiani F.E (1993): Responses of women to snow shoveling and snow blowing. Circulation, 88, 610 .

Smolander, J., Louhevaara, V., Ahonen, E., Polari, J. and Klen, T. (1995): Energy expenditure and clearing snow: a comparison of shovel and snow pusher. Ergonomics, 38, 794-753, doi: 10.1080/00140139508925146.

Suda, T., Nakagawa, K., Miyake, S., Sasaki, T., and Katoh, M. (1990): Physiological responses to snow shoveling observed in aged men. Ed. Kaneko. Fitness for the Aged, Disabled and Industrial Worker. Human Kinetics, Illinois, 75-78 pp.

Vocac, Z., H. Bell, E. Bautz-Holter, K. Rodahl (1975): Oxygen uptake/heart rate relationship in leg and arm exercise sitting and standing. J. Appl. Physiol., 39 (1), 54-59, doi: 10.1152/jappl.1975.39.1.54.

Yamashita, K., Miura M., Lee S., Yoshioka (2003): Working Conditions and Cardiorespiratory Responses during Snow Removal. (in Japanese) Journal of The Japanese Physical Therapy Association, 30, (5), 273-279. 